\title{
Highway Expenditures and Associated Customer Satisfaction: A Case Study
}

\author{
Alexander Paz, ${ }^{1}$ Hanns de la Fuente-Mella, ${ }^{2}$ Ashok Singh, ${ }^{3}$ \\ Rebecca Conover, ${ }^{1}$ and Heather Monteiro ${ }^{3}$ \\ ${ }^{1}$ Department of Civil and Environmental Engineering, University of Nevada, Las Vegas, 4505 S. Maryland Parkway, \\ P.O. Box 454015, Las Vegas, NV 89154, USA \\ ${ }^{2}$ Facultad de Ciencias Económicas y Administrativas, Pontificia Universidad Católica de Valparaíso, Avenida Brasil 2830, \\ 2340031 Valparaíso, Chile \\ ${ }^{3}$ William F. Harrah College of Hotel Administration, University of Nevada, Las Vegas, 4505 Maryland Parkway, Box 6021, \\ Las Vegas, NV 89154-4015, USA
}

Correspondence should be addressed to Hanns de la Fuente-Mella; hanns.delafuente@ucv.cl

Received 4 January 2016; Accepted 9 March 2016

Academic Editor: Roberto Dominguez

Copyright @ 2016 Alexander Paz et al. This is an open access article distributed under the Creative Commons Attribution License, which permits unrestricted use, distribution, and reproduction in any medium, provided the original work is properly cited.

\begin{abstract}
This study analyzes the satisfaction of the Nevadans with respect to their highway transportation system and the corresponding expenditures of Nevada Department of Transportation (NDOT). A survey questionnaire was designed to capture the opinions of the Nevadans (customers) about a number of characteristics of their transportation system. Data from the financial data warehouse of the NDOT was used to evaluate expenditures. Multinomial probit models were estimated to study the correlations between customers' opinion and the government expenditures in transportation. The results indicate the customer satisfaction is decreasing with respect to traffic safety throughout Northwestern and Southern Nevada highways. In addition, users of Northwestern highways are more likely to be satisfied, compared to their counterparts, with increasing construction spending to reduce the time taken to complete construction projects. In Southern Nevada highways, customers' satisfaction increases with the expenditures associated with reduction of congestion. These insights are examples of the conclusions that were obtained as a consequence of simultaneously considering customer satisfaction and the corresponding expenditures in transportation.
\end{abstract}

\section{Introduction}

Customer satisfaction surveys help reveal customer desires and preferences and have been widely used by private industries. The private sector typically allocates significant resources to learn what their customers want in order to maximize profits, increase shareholder return, and gain competitive advantage. This approach is rarely used by public entities, even though residents are the main shareholders of public services and deserve to be considered [1].

Despite the immense amount of cost and time allocated to public projects, the public sector has several reasons for its lack of interest in customer input. These reasons include the monopoly these departments have on service regardless of public support, laws dictating the department's responsibilities, and an "accountability to elected officials," according to
Sorel [1]. In recent years, however, there has been an increased desire to include the public in the decision-making process, based on the desire to "build community, generate support, agreement, and momentum for public actions, remediate democratic and citizenship deficits, address complex governance problems, and take advantage of transformations in the expectations and capacities of ordinary people". Unfortunately, the public does not have significant confidence in government entities. According to Kline [2], a Gallup survey from 1997 showed that

90 percent of respondents believed that 'people in government waste a lot of money we pay in taxes,' and that 66 percent of respondents believed that while the American 'system of government is good, the people running it are incompetent.' [2] 
Without satisfaction surveys, problems such as these may never be revealed [2].

Customer satisfaction surveys have been used for a long time to measure public opinion in industry. However, they are a time consuming and expensive investment. Because of this, it is important that the results of these surveys are interpreted correctly and the results effectively integrated into business operations. If customer input is deemed significant to an industry's definition of success, it is important that input is sought often, that decision makers are constantly aware of the effects of their decisions on the customer [3], and that the customer is made aware of those decisions that will affect them [1].

In 2000, the Institute of Transportation Engineers (ITE) and the Federal Highway Administration (FHWA) led a national dialogue on transportation operations with state Departments of Transportation (DOTs) across the country to develop a definition of success and a list of performance indicators, which included results from customer satisfaction surveys [4]. In 2009, the National Cooperative Highway Research Program (NCHRP) and the Transportation Research Board (TRB) commissioned a manual of guidelines for performing customer satisfaction surveys for DOTs across the country. In total, 31 states were represented in the review, which highlighted the methods, purposes, successes, and failures they experienced when utilizing a survey [5]. Since this manual was published, DOTs from over a dozen states throughout the US have conducted similar satisfaction surveys, including Nevada in 2009 [6], for the purpose of tracking progress over time or as a means of comparing strengths and weaknesses with those of neighboring states. Additionally, the TRB manual provides information on various survey methods available to designers including the pros and cons of each [7]. The most expensive option, the personal interview, requires a huge investment in training interviewers but provides the most in-depth results [7].

Independent of initiatives from the public sector, there can be inconsistent results from customer surveys. For example, customers may feel that safety is the greatest priority on Nevada roads; simultaneously, they may think that safety expenditures may appear to be an inexcusable drain on resources. This disagreement could cause one analyst to promote increased spending on road safety features and another to promote reduced spending on safety in favor of other projects, such as adding new roads.

Thus, the intent of this research is to combine the results of the 2014 Customer Satisfaction Survey and the Business Intelligence Review of the Nevada Department of Transportation (NDOT) financial database. Combining the survey responses with the annual expenditure of NDOT has the potential of showing where spending has been successful and where it has been wasteful. With this information, NDOT could plan budgets and allocate funds to address the needs of Nevada residents in a more optimal manner. Additionally, the analysis has the potential of being applied to other public departments with limited budgets where public opinion, not sales, profits, or shareholder constraints, is the priority.

\section{Methodology}

A questionnaire was designed and implemented to survey the Nevadans on their opinions about congestion, construction, maintenance, safety, and funding for state roads. For this survey, it was important to determine the differences among the three districts within NDOT's jurisdiction, District 1: Southern Nevada; District 2: Northwestern Nevada; and District 3: Northeastern Nevada. Moreover, occupational subpopulations were targeted in the questionnaire and included business executives, school district employees, firefighters, police officers, tourists and tourism workers, commercial truck drivers, and warehousing and distribution managers. The respondents answered 24 questions related to experiences on the Nevada roads, five demographic questions for weighing and location purposes, and one open-ended question that allowed for additional suggestions and concerns.

A total of 4,285 survey responses were collected by the Cannon Survey Center (CSC), operated within the University of Nevada, Las Vegas (UNLV). CSC collected 2,636 responses by online and telephone surveys. In addition, to reach the occupational subpopulation goals, 1,649 responses were collected from several smaller population groups independently from the CSC surveys, using a small subcontractor and UNLV's Transportation Research Center (TRC). The sample size of each of these subpopulations was determined to obtain a representative sample for the corresponding size of the subpopulations using information from the US Bureau of Labor Statistics [8].

Considering the discrete characteristic of the opinions, various discrete choice model specifications were tested seeking to better capture the interdependencies between opinions and potential explanatory variables. Some of the specifications that were tested included logit, mixed-logit, and probit models. In this study, the best model results in terms of higher explanatory power were obtained using probit specifications. Probit models are characterized by the assumption of normally distributed error terms. That is, the distribution of the unobserved factors is normal. This assumption makes probit models very attractive and able to capture complex interdependencies. Other alternative models such as logit are very restrictive because they imply the assumption of independent and identically distribute extreme value error terms. Most discrete choice models can handle multinomial, discrete-ordered, and binary specifications [9]. When the data includes an increasing or decreasing order of choices, a discrete-ordered specification enables using this information for potentially increasing the explanatory power of the model [10].

The probit models that were developed in this study provided insights into how the Nevadans felt regarding their highway system. These insights were correlated with the expenditure trends that may or may not have affected these feelings or opinions. The financial database of Nevada Department of Transportation (NDOT) was used for studying this potential correlation. This database provides information about how resources were used across the highway system. The analysis period included fiscal years 1999 through 2014. 
TABLE 1: Congestion acceptability as a function of travel time satisfaction. District 1 (Southern Nevada).

\begin{tabular}{|c|c|c|c|c|}
\hline Variable & Likelihood estimate & Standard error & $Z$ value & $\operatorname{Pr}(>|z|)$ \\
\hline (Intercept) & -1.513 & 0.1203 & -12.58 & $<2 e-16^{* * *}$ \\
\hline Con1 Satisfied & 0.8084 & 0.1254 & 6.447 & $1.14 e-10^{* * *}$ \\
\hline Con1 Neutral & 1.6258 & 0.1333 & 12.2 & $<2 e-16^{* * *}$ \\
\hline Con1 Dissatisfied & 2.557 & 0.146 & 17.51 & $<2 e-16^{* * *}$ \\
\hline Con1 Very Dissatisfied & 3.0511 & 0.2113 & 14.441 & $<2 e-16^{* * *}$ \\
\hline
\end{tabular}

Significance codes: $0=* * *, 0.001=* *, 0.01=*, 0.05=\#$.

TABLE 2: Congestion acceptability as a function of congestion reduction satisfaction. District 1 (Southern Nevada).

\begin{tabular}{|c|c|c|c|c|}
\hline Variable & Likelihood estimate & Standard error & $Z$ value & $\operatorname{Pr}(>|z|)$ \\
\hline (Intercept) & -1.3267 & 0.1534 & -8.647 & $<2 e-16^{* * *}$ \\
\hline Con2 Satisfied & 0.3713 & 0.1588 & 2.339 & $0.0194^{*}$ \\
\hline Con2 Neutral & 1.1181 & 0.1624 & 6.885 & $5.78 e-12^{* * *}$ \\
\hline Con2 Dissatisfied & 2.1405 & 0.1652 & 12.956 & $<2 e-16^{* * *}$ \\
\hline Con2 Very Dissatisfied & 2.9922 & 0.2259 & 13.245 & $<2 e-16^{* * *}$ \\
\hline
\end{tabular}

Significance codes: $0=* * *, 0.001=* *, 0.01=*, 0.05=\#$.

TABLE 3: Congestion acceptability as a function of travel time satisfaction. District 2 (Northwestern Nevada).

\begin{tabular}{|c|c|c|c|c|}
\hline Variable & Likelihood estimate & Standard error & $Z$ value & $\operatorname{Pr}(>|z|)$ \\
\hline (Intercept) & -1.5414 & 0.1361 & -11.325 & $<2 e-16^{* * *}$ \\
\hline Con1 Satisfied & 0.4923 & 0.1546 & 3.185 & $0.00145^{* *}$ \\
\hline Con1 Neutral & 1.333 & 0.1844 & 7.227 & $4.92 e-13^{* * *}$ \\
\hline Con1 Dissatisfied & 1.9075 & 0.2783 & 6.855 & $7.14 e-12^{* * *}$ \\
\hline Con1 Very Dissatisfied & 6.7522 & 142.3995 & 0.047 & 0.96218 \\
\hline
\end{tabular}

Significance codes: $0=* * *, 0.001=* *, 0.01=*, 0.05=\#$.

TABLE 4: Congestion acceptability as a function of congestion reduction satisfaction. District 2 (Northwestern Nevada).

\begin{tabular}{|c|c|c|c|c|}
\hline Variable & Likelihood estimate & Standard error & $Z$ value & $\operatorname{Pr}(>|z|)$ \\
\hline (Intercept) & -1.5087 & 0.1656 & -9.112 & $<2 e-16^{* * *}$ \\
\hline Con2 Satisfied & 0.2952 & 0.1847 & 1.598 & 0.11 \\
\hline Con2 Neutral & 0.8166 & 0.2032 & 4.019 & $5.85 e-05^{* * *}$ \\
\hline Con2 Dissatisfied & 1.4162 & 0.2098 & 6.751 & $1.46 e-11^{* * *}$ \\
\hline Con2 Very Dissatisfied & 3.0097 & 0.5249 & 5.734 & $9.80 e-09^{* * *}$ \\
\hline
\end{tabular}

Significance codes: $0=* * *, 0.001=* *, 0.01=*, 0.05=\#$.

2.1. Results from Probit Models for Congestion. Three questions were asked in the Congestion section of the survey:

(1) How satisfied are you with your highway travel time?

(2) How satisfied are you with the efforts being made to reduce congestion on freeways?

(3) Is the level of congestion on Nevada highways acceptable?

The first two questions were asked on a five-point scale from "Very Satisfied" to "Very Dissatisfied." The last question was a simple binary "yes or no" question. All three questions had a majority of positive responses; however, to improve satisfaction, we must determine what factors or combination of factors led some respondents to answer that they were either "Dissatisfied" or "Very Dissatisfied."
A probit model was developed to understand how the responses of the two prefacing questions influenced the response of the final question: "Is the level of congestion on Nevada highways acceptable?” A model was developed for each of NDOT's three districts.

In Table 1, "Conl Satisfied" represents a "Satisfied" response for the first question about Congestion. A model, with all coefficients equal to zero, represented the likelihood of a respondent indicating that they were "Very Satisfied" with either their highway travel time (Congestion Question 1) or the efforts being made to reduce congestion on freeways (Congestion Question 2) while simultaneously responding that the level of congestion on Nevada highways was not acceptable.

As the level of satisfaction decreased with each question, shown in Tables 1-4, the likelihood of responding that the 
TABle 5: Perception of safety as a function of debris removal satisfaction. District 1 (Southern Nevada).

\begin{tabular}{|c|c|c|c|c|}
\hline Variable & Likelihood estimate & Standard error & $Z$ value & $\operatorname{Pr}(>|z|)$ \\
\hline (Intercept) & 1.54616 & 0.09607 & 16.093 & $<2 e-16^{* * *}$ \\
\hline Safe 1 Satisfied & -0.36739 & 0.10344 & -3.552 & $0.000382^{* * *}$ \\
\hline Safe 1 Neutral & -1.05738 & 0.11427 & -9.254 & $<2 e-16^{* * *}$ \\
\hline Safe 1 Dissatisfied & -1.3742 & 0.12284 & -11.187 & $<2 e-16^{* * *}$ \\
\hline Safe 1 Very Dissatisfied & -1.97689 & 0.19677 & -10.047 & $<2 e-16^{* * *}$ \\
\hline
\end{tabular}

Significance codes: $0=* * *, 0.001=* *, 0.01=*, 0.05=\#$.

TABLE 6: Perception of safety as a function of roadway striping satisfaction. District 1 (Southern Nevada).

\begin{tabular}{|c|c|c|c|c|}
\hline Variable & Likelihood estimate & Standard error & $Z$ value & $\operatorname{Pr}(>|z|)$ \\
\hline (Intercept) & 1.5011 & 0.1286 & 11.672 & $<2 e-16^{* * *}$ \\
\hline Safe 2 Satisfied & -0.1699 & 0.1356 & -1.253 & 0.21 \\
\hline Safe 2 Neutral & -0.8281 & 0.1419 & -5.835 & $5.38 e-09^{* * *}$ \\
\hline Safe 2 Dissatisfied & -1.165 & 0.1409 & -8.269 & $<2 e-16^{* * *}$ \\
\hline Safe 2 Very Dissatisfied & -1.6358 & 0.1751 & -9.342 & $<2 e-16^{* * *}$ \\
\hline
\end{tabular}

Significance codes: $0=* * *, 0.001=* *, 0.01=*, 0.05=\#$.

TABLE 7: Perception of safety as a function of signage satisfaction. District 1 (Southern Nevada).

\begin{tabular}{lcccc}
\hline Variable & Likelihood estimate & Standard error & $Z$ value & $\operatorname{Pr}(>|z|)$ \\
\hline (Intercept) & 1.36651 & 0.09895 & 13.81 & 0.0737 \\
Safe 3 Satisfied & -0.18946 & 0.10593 & -1.789 & $6.65 e-08^{* * *}$ \\
Safe 3 Neutral & -0.62453 & 0.11565 & -5.4 & -10.876 \\
Safe 3 Dissatisfied & -1.36651 & 0.12564 & -9.668 & $<2 e-16^{* * *}$ \\
Safe 3 Very Dissatisfied & -2.1387 & 0.22122 & $<2 e-16^{* * *}$ \\
\hline
\end{tabular}

Significance codes: $0=* * *, 0.001=* *, 0.01=*, 0.05=\#$.

level of congestion on Nevada highways was unacceptable increased. A strong trend could not be discerned from District 3. In Districts 1 (Southern Nevada) and 2 (Northwestern Nevada), a decreased level of satisfaction was indicated for both prefacing questions. Likely, the lack of a trend may be due to the small sample size of District 3, as the population is roughly $3 \%$ of the entire state. Another possibility was the strong rural influence in this district; that is, congestion was less of an issue for drivers in District 3.

In both Districts 1 and 2, analysis showed that dissatisfaction with highway travel time was the most influential predictor of a "No" response for the acceptability of the level of congestion on Nevada highways. This implied that if highway travel time were addressed by NDOT, a greater number of respondents who are currently dissatisfied would feel that the level of congestion on Nevada highways was acceptable.

2.2. Results from Probit Models for Safety. A similar analysis was performed within the "Safety" segment of the survey. In that section, there were six prefacing questions and one summary question. The prefacing questions sought the respondent's level of satisfaction regarding debris removal, roadway striping, signage, lighting, drainage, and snow and ice removal. The respondents answered on a five-point scale from "Very Satisfied" to "Very Dissatisfied." The final summary question was: "Overall, how safe do you feel when traveling on highways in Nevada?" The last question was asked on a four-point scale to create a definitive positive or negative response ranging from "Very Safe" to "Very Unsafe."

For each district, different prefacing questions were significant when predicting a respondent's overall perception of safety on Nevada highways. In the following models, the initial intercept estimate was the likelihood that a "Very Satisfied" respondent considered that he or she was safe (either "Safe" or "Very Safe"). Therefore, as satisfaction levels decreased, it was expected that the estimates would decrease toward a negative perception of safety.

In determining the overall level of safety that users perceive regarding Nevada highways, the models for District 1 , found in Tables $5-10$, showed that all factors were at least partially significant. Safety Question 1, concerning debris removal, showed the greatest effects implying that better removal of debris by NDOT would have a greater effect on the overall perception of safety. The two weather-related topics, drainage and snow and ice removal, were not significant for the model, most likely because these issues are more prevalent in the northern districts.

The models for District 2, shown in Tables 11-16, showed weaker correlations than did the models for District 1 . The model for signage, shown in Table 13, appears to be the most significant predictor of the perception of safety 
TABLE 8: Perception of safety as a function of lighting satisfaction. District 1 (Southern Nevada).

\begin{tabular}{|c|c|c|c|c|}
\hline Variable & Likelihood estimate & Standard error & $Z$ value & $\operatorname{Pr}(>|z|)$ \\
\hline (Intercept) & 1.4342 & 0.1318 & 10.881 & $<2 e-16^{* * *}$ \\
\hline Safe 4 Satisfied & -0.2172 & 0.1382 & -1.572 & 0.116 \\
\hline Safe 4 Neutral & -0.634 & 0.1428 & -4.441 & $8.96 e-06^{* * *}$ \\
\hline Safe 4 Dissatisfied & -1.0483 & 0.1452 & -7.218 & $5.27 e-13^{* * *}$ \\
\hline Safe 4 Very Dissatisfied & -1.7927 & 0.1983 & -9.04 & $<2 e-16^{* * *}$ \\
\hline
\end{tabular}

Significance codes: $0=* * *, 0.001=* *, 0.01=*, 0.05=\#$.

TABle 9: Perception of safety as a function of drainage satisfaction. District 1 (Southern Nevada).

\begin{tabular}{lcccc}
\hline Variable & Likelihood estimate & Standard error & $Z$ value & \multicolumn{2}{c}{$\operatorname{Pr}(>|z|)$} \\
\hline (Intercept) & 1.3145 & 0.13785 & 9.535 & 0.453 \\
Safe 5 Satisfied & -0.06597 & 0.14562 & -0.453 & 0.6505 \\
Safe 5 Neutral & -0.30331 & 0.14711 & -2.062 & $0.0392^{*}$ \\
Safe 5 Dissatisfied & -0.90053 & 0.14857 & -6.062 & $1.35 e-09^{* * *}$ \\
Safe 5 Very Dissatisfied & -1.40256 & 0.18117 & -7.742 & $9.80 e-15^{* * *}$ \\
\hline
\end{tabular}

Significance codes: $0=* * *, 0.001=* *, 0.01=*, 0.05=\#$.

TABle 10: Perception of safety as a function of snow and ice removal satisfaction. District 1 (Southern Nevada).

\begin{tabular}{lcccc}
\hline Variable & Likelihood estimate & Standard error & $Z$ value & $\operatorname{Pr}(>|z|)$ \\
\hline (Intercept) & 1.15871 & 0.10897 & 10.633 & -0.837 \\
Safe 6 Satisfied & -0.09965 & 0.11908 & -2.029 & 0.4027 \\
Safe 6 Neutral & -0.23647 & 0.11657 & $-0.0425^{* *}$ \\
Safe 6 Dissatisfied & -0.95063 & 0.17149 & -5.543 & $2.97 e-08^{* * *}$ \\
Safe 6 Very Dissatisfied & -1.32292 & 0.28433 & -4.653 & $3.27 e-06^{* * *}$ \\
\hline
\end{tabular}

Significance codes: $0=* * *, 0.001=* *, 0.01=*, 0.05=\#$.

TABLE 11: Perception of safety as a function of debris removal satisfaction. District 2 (Northwestern Nevada).

\begin{tabular}{|c|c|c|c|c|}
\hline Variable & Likelihood estimate & Standard error & $Z$ value & $\operatorname{Pr}(>|z|)$ \\
\hline (Intercept) & 1.73891 & 0.16147 & 10.769 & $<2 e-16^{* * *}$ \\
\hline Safe 1 Satisfied & -0.06017 & 0.18748 & -0.321 & 0.7483 \\
\hline Safe 1 Neutral & -0.37324 & 0.2457 & -1.519 & 0.1287 \\
\hline Safe 1 Dissatisfied & -1.01331 & 0.25816 & -3.925 & $8.67 e-05^{* * *}$ \\
\hline Safe 1 Very Dissatisfied & -1.30818 & 0.76575 & -1.708 & $0.0876^{\#}$ \\
\hline
\end{tabular}

Significance codes: $0=* * *, 0.001=* *, 0.01=*, 0.05=\#$.

TABLE 12: Perception of safety as a function of roadway striping satisfaction. District 2 (Northwestern Nevada).

\begin{tabular}{lcccc}
\hline Variable & Likelihood estimate & Standard error & $Z$ value & 7.222 \\
\hline (Intercept) & 2.0738 & 0.2872 & -1.252 & $5.14 e-13^{* * *}$ \\
Safe 2 Satisfied & -0.3795 & 0.303 & -2.238 & 0.21049 \\
Safe 2 Neutral & -0.7558 & 0.3377 & -2.686 & $0.02522^{*}$ \\
Safe 2 Dissatisfied & -0.862 & 0.3209 & -2.873 & $0.00724^{* *}$ \\
Safe 2 Very Dissatisfied & -1.3993 & 0.487 & $0.00406^{* *}$ \\
\hline
\end{tabular}

Significance codes: $0=* * *, 0.001=* *, 0.01=*, 0.05=\#$.

and was significant at all satisfaction levels. Also in this model, weather-related questions were not more significant to residents of District 2 than to those of District 1 , even though rain and snow were more common in the north.

In District 3, none of the primary questions provided a significant estimate of the users' perceptions of safety. Again, this may be due to the small sample size coming from District 3.

Because there is strong evidence to indicate that customers are highly concerned with poor safety conditions on Nevada highways, the opinions of the greatest number of drivers might be improved by addressing safety issues on 
TABLE 13: Perception of safety as a function of signage satisfaction. District 2 (Northwestern Nevada).

\begin{tabular}{|c|c|c|c|c|}
\hline Variable & Likelihood estimate & Standard error & $Z$ value & $\operatorname{Pr}(>|z|)$ \\
\hline (Intercept) & 2.219 & 0.2734 & 8.115 & $4.86 e-16^{* * *}$ \\
\hline Safe 3 Satisfied & -0.5844 & 0.2864 & -2.04 & $0.041306^{*}$ \\
\hline Safe 3 Neutral & -1.1645 & 0.3526 & -3.302 & $0.000959^{* * *}$ \\
\hline Safe 3 Dissatisfied & -1.1082 & 0.3608 & -3.071 & $0.002131^{* *}$ \\
\hline Safe 3 Very Dissatisfied & -2.4723 & 0.4853 & -5.094 & $3.51 e-07^{* * *}$ \\
\hline
\end{tabular}

Significance codes: $0=* * *, 0.001=* *, 0.01=*, 0.05=\#$.

TABLE 14: Perception of safety as a function of lighting satisfaction. District 2 (Northwestern Nevada).

\begin{tabular}{|c|c|c|c|c|}
\hline Variable & Likelihood estimate & Standard error & $Z$ value & $\operatorname{Pr}(>|z|)$ \\
\hline (Intercept) & 2.303 & 0.376 & 6.125 & $9.10 e-10^{* * *}$ \\
\hline Safe 4 Satisfied & -0.621 & 0.3884 & -1.599 & 0.1099 \\
\hline Safe 4 Neutral & -0.802 & 0.4205 & -1.907 & $0.0565^{\#}$ \\
\hline Safe 4 Dissatisfied & -0.9721 & 0.406 & -2.394 & $0.0167^{*}$ \\
\hline Safe 4 Very Dissatisfied & -2.3996 & 0.5125 & -4.682 & $2.84 e-06^{* * *}$ \\
\hline
\end{tabular}

Significance codes: $0=* * *, 0.001=* *, 0.01=*, 0.05=\#$.

TABLE 15: Perception of safety as a function of drainage satisfaction. District 2 (Northwestern Nevada).

\begin{tabular}{lcccc}
\hline Variable & Likelihood estimate & Standard error & \multicolumn{2}{c}{$Z$ value } \\
\hline (Intercept) & 1.9808 & 0.2965 & 6.68 & $2.39 e-11^{* * *}$ \\
Safe 5 Satisfied & -0.1621 & 0.3144 & -0.516 & 0.606164 \\
Safe 5 Neutral & -0.5757 & 0.3385 & -1.701 & $0.088972^{\#}$ \\
Safe 5 Dissatisfied & -1.0519 & 0.3367 & -3.124 & $0.001785^{* *}$ \\
Safe 5 Very Dissatisfied & -1.632 & 0.487 & -3.351 & $0.000805^{* * *}$ \\
\hline
\end{tabular}

Significance codes: $0=* * *, 0.001=* *, 0.01=*, 0.05=\#$.

TABLE 16: Perception of safety as a function of snow and ice removal satisfaction. District 2 (Northwestern Nevada).

\begin{tabular}{|c|c|c|c|c|}
\hline Variable & Likelihood estimate & Standard error & $Z$ value & $\operatorname{Pr}(>|z|)$ \\
\hline (Intercept) & 1.9145 & 0.2478 & 7.727 & $1.1 e-14^{* * *}$ \\
\hline Safe 6 Satisfied & -0.1583 & 0.2677 & -0.591 & 0.554384 \\
\hline Safe 6 Neutral & -0.1457 & 0.3353 & -0.434 & 0.663941 \\
\hline Safe 6 Dissatisfied & -0.8821 & 0.2889 & -3.054 & $0.002260^{* *}$ \\
\hline Safe 6 Very Dissatisfied & -1.4838 & 0.3934 & -3.772 & $0.000162^{* * *}$ \\
\hline
\end{tabular}

Significance codes: $0=* * *, 0.001=* *, 0.01=*, 0.05=\#$.

roads, specifically deploying countermeasures in the locations with the most safety issues. Clearly, this requires a complete traffic-safety management process involving network screening, diagnosis, countermeasure selection, appraisal, and evaluation.

2.3. The Relationship between Customer Satisfaction and Government Spending. The expenditure data that was accessible covered fiscal years 1999 through 2014. Expenditures were separated both by district and category. There were 50 possible expenditure categories, only five of which could be directly related to a given question regarding customer satisfaction and had consistent data across the time period and districts. These five categories were construction, construction engineering, maintenance, roadway design, and traffic.
Regarding an expenditure trend analysis, the most appropriate one for this study and the method used in this research was a time-series regression [11]. Unfortunately, a timeseries regression did not yield statistically significant trends for all five expenditure categories (see Table 17). Significant results included maintenance and roadway design and traffic for District 1 and maintenance for Districts 2 and 3. In large part, expenses were random over the time period and had too large variance to confidently assign a mean annual expense or average rate of change in expenditures (see Table 17). Thus, the average annual growth (or average annual decline) could not be included as a variable in a potential model measuring the relationship between satisfaction and expenditure. Therefore, the true value of the expense was compared to the levels of satisfaction. 
TABLE 17: Estimates for the expenditure trend categories.

\begin{tabular}{|c|c|c|c|c|c|c|}
\hline & Mean & Standard deviation & Trend estimate & Standard error & $t$-statistics & $\operatorname{Pr}(>|t|)$ \\
\hline \multicolumn{7}{|c|}{ District 1} \\
\hline Construction & 396372.6 & 670038.2 & 38794.54 & 36156.06 & 1.0729 & 0.3014 \\
\hline Construction engineering & 7582574 & 1149534 & 53298.14 & 62938.55 & 0.8468 & 0.4113 \\
\hline Maintenance & 17059451 & 4659285 & 700596.9 & 182622.0 & 3.8363 & $0.0018^{* *}$ \\
\hline Roadway design & 272945.8 & 378387.7 & 62035.85 & 13277.79 & 4.6721 & $0.0004^{* * *}$ \\
\hline Traffic & 9307.105 & 5434.873 & 504.43 & 273.68 & 1.8430 & $0.0086^{* *}$ \\
\hline \multicolumn{7}{|c|}{ District 2} \\
\hline Construction & 227817.1 & 481591.5 & 38108.16 & 25042.81 & 1.5217 & 0.1503 \\
\hline Construction engineering & 3666015 & 657684.5 & 50251.84 & 34390.40 & 1.4612 & 0.1660 \\
\hline Maintenance & 16860084 & 6034262 & 1117075 & 160037.60 & 6.9800 & $0.0000^{* * *}$ \\
\hline Roadway design & 12782.43 & 23525.46 & 795.51 & 1303.40 & 0.6103 & 0.5515 \\
\hline Traffic & 5903.336 & 4331.059 & -331.38 & 226.42 & -1.4635 & 0.1654 \\
\hline \multicolumn{7}{|c|}{ District 3} \\
\hline Construction & 258197.6 & 524008.7 & 39028.29 & 27504.34 & 1.4189 & 0.1778 \\
\hline Construction engineering & 3422544 & 559718.7 & 22305.39 & 30849.72 & 0.7230 & 0.4816 \\
\hline Maintenance & 14886381 & 5923932 & 629710.9 & 286815.4 & 2.1955 & 0.0455 \\
\hline Roadway design & 1894.336 & 5453.910 & -367.89 & 289.94 & -1.2688 & 0.2252 \\
\hline Traffic & 3719.804 & 2988.365 & -83.82 & 166.25 & -0.5041 & 0.6220 \\
\hline
\end{tabular}

Significance codes: $0=* * *, 0.001=* *, 0.01=*, 0.05=\#$.

TABLE 18: Comparison of survey question categories to expenditure categories.

\begin{tabular}{lc}
\hline Survey question category & Expenditure category \\
\hline Construction & Construction \\
& Construction engineering \\
Safety & Maintenance \\
\hline Congestion & Roadway design \\
\hline
\end{tabular}

Data for financial expenditure originally was divided into 50 expenditure categories. Survey questions were divided into groups comparing relevant expenditure data, either directly or indirectly. These groups were construction, safety, and congestion. The relationships between the survey question categories and the expenditure categories are shown in Table 18.

To measure and confirm the relationships between the two data sets, nonparametric correlations were established using Spearman's Rho and factor analysis. After performing the factor and correlation analyses, one survey question showed a significant correlation with the given expenditures. A 2-tailed $p$ value of 0.10 was used to determine statistical significance.

Table 19 shows the relationships between construction expenditures for District 2 and the five survey questions.

Significant Spearman's Rho correlation coefficient was found between Question 4 of the survey, "how satisfied are you with the amount of time it takes to complete construction projects?," and construction expenditures. Thus, as construction spending increased in District 2, dissatisfaction with construction times decreased.
TABLE 19: Construction correlation for District 2.

\begin{tabular}{lcc}
\hline $\begin{array}{l}\text { Construction } \\
\text { survey question }\end{array}$ & Construction \\
Const 1 & Significance & 0.220 \\
& $N$ & 0.414 \\
& Correlation coefficient & 16 \\
\hline \multirow{3}{*}{ Const 2} & Significance & 0.217 \\
& $N$ & 0.414 \\
Const 3 & Correlation coefficient & 16 \\
& Significance & -0.438 \\
& $N$ & 0.419 \\
Const 4 & Correlation coefficient & 16 \\
& Significance & -0.471 \\
& $N$ & 0.065 \\
Const 5 & Correlation coefficient & 16 \\
& Significance & -0.237 \\
& $N$ & 0.376 \\
\hline
\end{tabular}

Table 20 provides the relationships between congestion (traffic) expenditures for District 3 and the three questions of the survey about this criterion.

In Table 20, significant Spearman's Rho correlation coefficient was observed between Question 2, "how satisfied are you with the efforts being made to reduce congestion on freeways?"” and congestion (traffic) expenditures. Thus, as congestion (traffic) spending increased in District 3, dissatisfaction decreased. 
TABLE 20: Congestion correlation for District 3.

\begin{tabular}{lcc}
\hline $\begin{array}{l}\text { Traffic survey } \\
\text { question }\end{array}$ & $\begin{array}{c}\text { Traffic } \\
\text { expenditures }\end{array}$ \\
\hline \multirow{2}{*}{ Traff 1} & Correlation coefficient & -0.402 \\
& Significance & 0.123 \\
& $N$ & 16 \\
\hline \multirow{2}{*}{ Traff 2} & Correlation coefficient & -0.422 \\
& Significance & 0.100 \\
& $N$ & 16 \\
Traff 3 & Correlation coefficient & -0.122 \\
& Significance & 0.654 \\
& $N$ & 16 \\
\hline
\end{tabular}

TABLE 21: Congestion correlation for District 3 (factor analysis).

\begin{tabular}{lcc}
\hline Spearman's Rho & Traffic expenditures \\
\hline \multirow{3}{*}{ Factor } & Correlation coefficient & -0.452 \\
& Significance & 0.079 \\
$N$ & 16 \\
\hline
\end{tabular}

Table 21 shows the relationship between congestion (traffic) expenditures for District 3 and the factor analysis created for the three congestion questions using Spearman's Rho coefficients as a measure of nonparametric correlation and Cronbach's Alpha coefficient as a measure of reliability. Cronbach's Alpha (0.53) indicates a consistency suitable for the new factor [12].

Table 21 shows significant Spearman's Rho correlation coefficient for the relationship between congestion (traffic) expenditures and the factor analysis created for the three congestion questions in District 3. Thus, as congestion (traffic) spending increases in District 3, dissatisfaction decreases.

Finally, Table 22 displays the relationships between safety expenditures for District 3 and the survey questions about these criteria, using Spearman's Rho criteria.

Table 22 shows significant Spearman's Rho correlation coefficient for the relationship between Safety Question 1 and Safety Question 2 of the survey, concerning debris removal and road striping, respectively, and roadway design expenditures. Thus, additional spending increased dissatisfaction with both debris removal and roadway striping in District 3.

\section{Conclusion}

This study provides evidence of the level of satisfaction of the residents of Nevada decreases related to the safety conditions on Northwestern and Southern Nevada highways. Analysis confirmed several statistically significant relationships between customer satisfaction and government spending. In District 2, increasing construction spending resulted in increasing customer satisfaction with the amount of time it takes to complete construction projects. In District 3, the analysis confirmed that additional traffic expenditures increased satisfaction. In District 3, roadway design expenditures had an effect on user perception of both debris
TABLE 22: Safety correlation for District 3.

\begin{tabular}{|c|c|c|}
\hline $\begin{array}{l}\text { Safety survey } \\
\text { question }\end{array}$ & & $\begin{array}{c}\text { Roadway design } \\
\text { expenditures }\end{array}$ \\
\hline \multirow{3}{*}{ Safe 1} & Correlation coefficient & 0.497 \\
\hline & Significance & 0.050 \\
\hline & $N$ & 16 \\
\hline \multirow{3}{*}{ Safe 2} & Correlation coefficient & 0.487 \\
\hline & Significance & 0.056 \\
\hline & $N$ & 16 \\
\hline \multirow{3}{*}{ Safe 3} & Correlation coefficient & 0.115 \\
\hline & Significance & 0.671 \\
\hline & $N$ & 16 \\
\hline \multirow{3}{*}{ Safe 4} & Correlation coefficient & 0.000 \\
\hline & Significance & 1.000 \\
\hline & $N$ & 16 \\
\hline \multirow{3}{*}{ Safe 5} & Correlation coefficient & -0.350 \\
\hline & Significance & 0.183 \\
\hline & $N$ & 16 \\
\hline \multirow{3}{*}{ Safe 6} & Correlation coefficient & 0.016 \\
\hline & Significance & 0.954 \\
\hline & $N$ & 16 \\
\hline \multirow{3}{*}{ Safe 7} & Correlation coefficient & 0.239 \\
\hline & Significance & 0.372 \\
\hline & $N$ & 16 \\
\hline
\end{tabular}

removal and roadway striping. However, these roadway design expenditures had the unintended effect of making users less satisfied with these issues. This may be an efficiency issue because roadway design dollars are not going toward debris removal or roadway striping projects.

Several problems arose in the latter half of this research. First, confidence in the expenditure data was limited. Because there was only a finite breakdown of expenditure types, assumptions had to be made both when entering expenditure data at the source and when analyzing the data in the present. Second, comparing direct expenditures between districts was potentially misleading. Most of Nevada's population lives in District 1; moreover, there are different types of roads throughout the state. Attempts were made to account for this issue by weighting expenditure data using such factors as district population, Average Annual Daily Traffic (AADT), and road miles in each jurisdiction. Finally, only the raw data values for expenditures could be used when measuring the correlations. Had there been a time-series relationship, variables such as rate of growth of expenditure or rate of decline of expenditure could been confidently used in a model.

Further analysis should be conducted to determine if and where NDOT funding is being expended to better address the needs and perceptions of the transportation users in Nevada. It is recommended that additional studies be conducted to measure respondent satisfaction over time. Additional 
questions could include the duration of state or regional residency, the perception of changing conditions (e.g., improving conditions), and additional ranking questions.

\section{Competing Interests}

The authors declare that they have no competing interests.

\section{References}

[1] T. Sorel, "Great expectations," Public Roads, vol. 68, no. 1, pp. 10-15, 2004.

[2] J. J. Kline, "How quality award-winning governments handle customer service," Journal of Organizational Excellence, vol. 20, no. 3, pp. 41-47, 2001.

[3] R. Sloane and K. Stein, Using Customer Needs to Drive Transportation Decisions, Report 487, Transportation Research Board, 2003.

[4] Institute of Transportation Engineers, Transportation Operations-The National Dialogue Continues, Institute of Transportation Engineers, Washington, DC, USA, 2000.

[5] NuStats, "Putting Customer Research into Practice: Guidelines for Conducting, Reporting, and Using Customer Surveys Related to Highway Maintenance Operations," 2009, http:// onlinepubs.trb.org/onlinepubs/nchrp/docs/NCHRP20-07(260) FR_Volumel.pdf.

[6] The Center for Research Design and Analysis, Nevada Department of Transportation Customer Satisfaction Survey 2009, University of Nevada, Reno, Reno, Nev, USA, 2009.

[7] J. T. Israel, Alternative Designs and Methods for Customer Satisfaction Measurement, SatisFaction Strategies, Portland, Ore, USA, 2002.

[8] United States Department of Labor, Bureau of Labor Statistics, 2012.

[9] S. P. Washington, M. G. Karlaftis, and F. L. Mannering, Statistical and Econometric Methods for Transportation Data Analysis, Chapman \& Hall, Boca Raton, Fla, USA, 2003.

[10] UCLA: Institute for Digital Research and Education, $R$ Data Analysis Examples: Ordinal Logistic Regression, 2015, http://www.ats.ucla.edu/stat/r/dae/ologit.htm.

[11] B. Kittel and H. Obinger, "Political parties, institutions, and the dynamics of social expenditure in times of austerity," Journal of European Public Policy, vol. 10, no. 1, pp. 20-45, 2003.

[12] M. C. Rodriguez and Y. Maeda, "Meta-analysis of coefficient alpha," Psychological Methods, vol. 11, no. 3, pp. 306-322, 2006. 


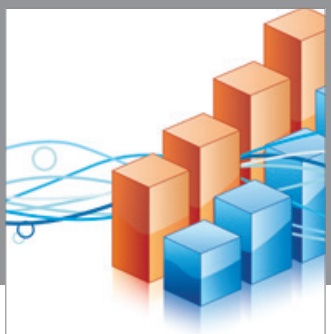

Advances in

Operations Research

vatem alat4

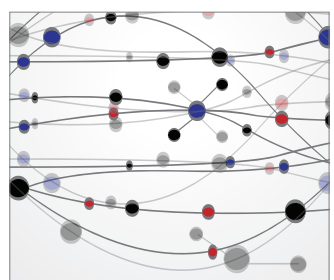

\section{The Scientific} World Journal
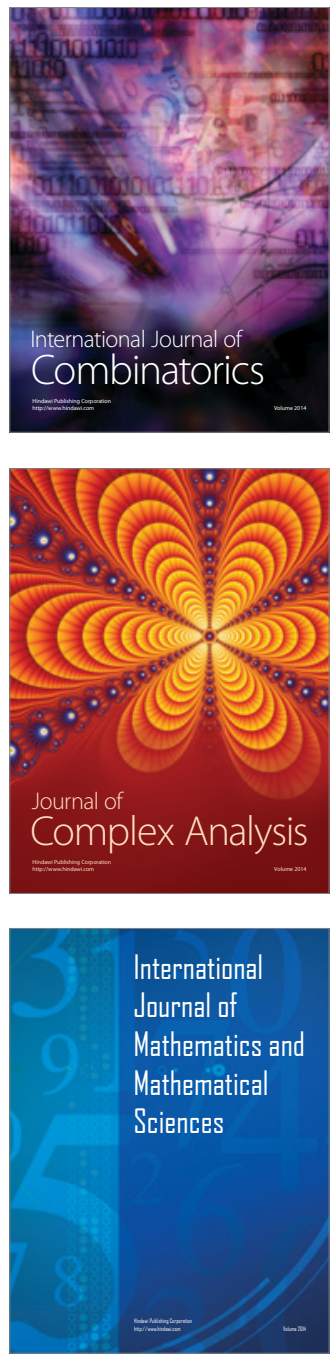
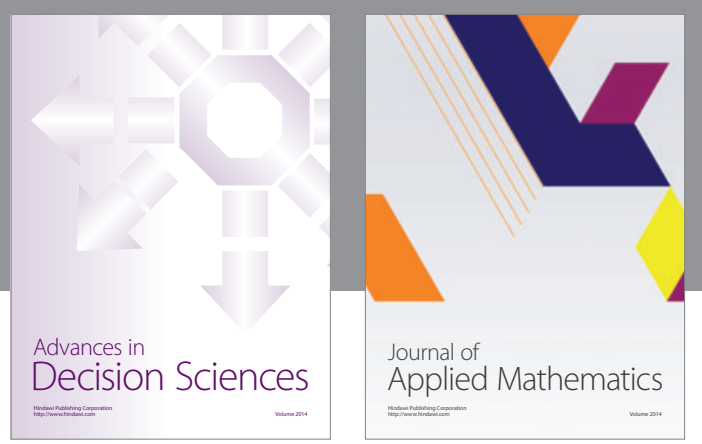

Algebra

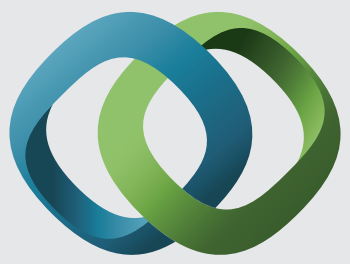

\section{Hindawi}

Submit your manuscripts at

http://www.hindawi.com
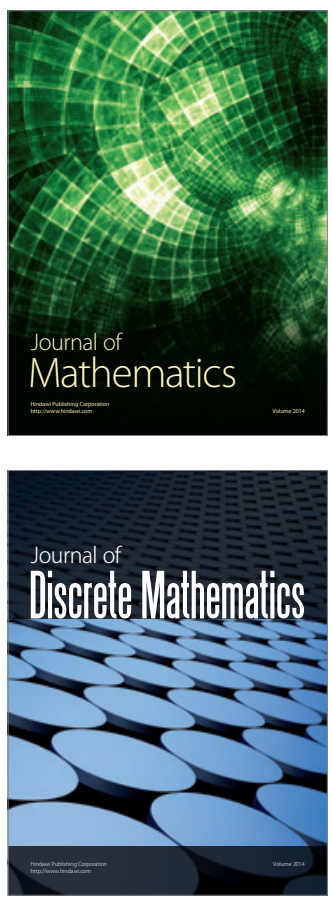

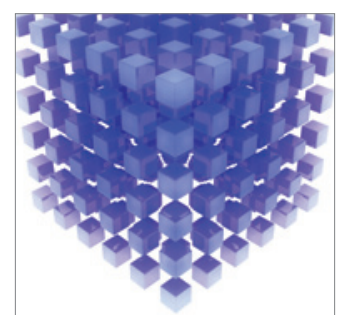

Mathematical Problems in Engineering
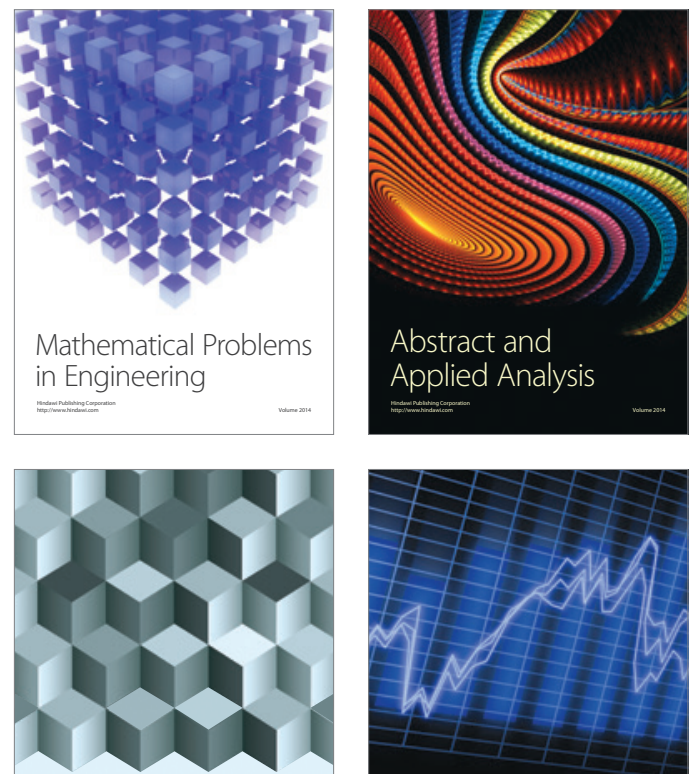

Journal of

Function Spaces

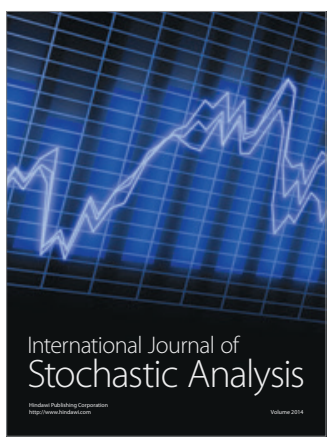

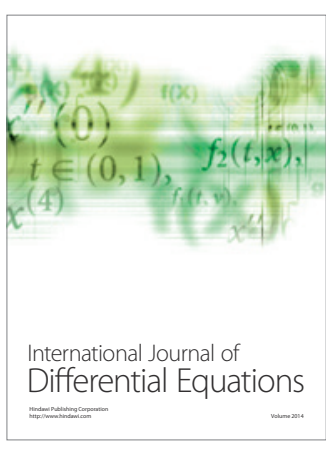
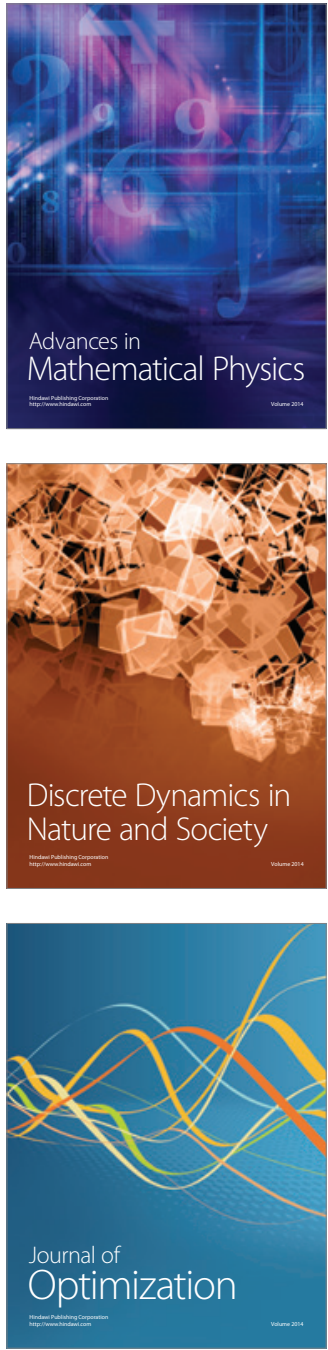